\title{
Estimation of Traffic Arrival Pattern at Signalized Intersection using ARIMA Model
}

\author{
Saurav Barua \\ Lecturer, Department of Civil \\ Engineering, University of \\ Information Technology and \\ Sciences, Dhaka, Bangladesh
}

\author{
Anik Das \\ Lecturer, Department of Civil \\ Engineering, University of \\ Information Technology and \\ Sciences, Dhaka, Bangladesh
}

\author{
Kamol Chandra Roy \\ Lecturer, Department of Civil \\ Engineering, Stamford \\ University, Dhaka, Bangladesh
}

\begin{abstract}
Traffic arrival pattern is an important parameter in delay estimation at signalized intersection. Usually, arrival pattern is assumed to be Poisson distribution. However, it varies widely under different volume-capacity ratio at signalized intersection of an arterial road. Therefore, conventional Poisson model cannot predict traffic pattern properly. A time series ARIMA model was proposed in this study to compare with Poisson model. A Paramics simulation model of Route 18 arterial road located in New Brunswick, New Jersey, USA was studied for the research purpose. Three intersections in Route 18-Naricon Place intersection, South Woodland Avenue intersection and West Ferris Street intersectionwere considered where traffic arrivals were under dispersed, random and over dispersed under different simulation scenarios respectively. Later, traffic arrival patterns obtained from simulation were compared with Poisson and ARIMA model using SAS statistical software. Arrival headway, vehicle counts per signal cycle, variance to mean ratio were considered and statistical analysis were performed between two candidate models. Study found that, ARIMA model predicts arrival pattern more accurately than Poisson model.
\end{abstract}

\section{General Terms}

Traffic Engineering, Computer Simulation, Times Series Model.

\section{Keywords}

Traffic arrival pattern, Signalized intersection, Poisson, ARIMA, Paramics simulation.

\section{INTRODUCTION}

In this study, portion of Route 18 in New Brunswick, New Jersey, USA was taken for model in Paramics simulation. To observe arrival patterns at different demand levels were considered. All signals were optimized using Synchro for the corresponding traffic demands obtained in the Paramics model. In this study, the simulation time period was to be taken ten hours and numbers of simulation required for each demand level were determined based on statistical significance. Traffic arrivals of signalized intersections are studied in order to study the fitness of these arrivals to Poisson probability distribution. In many situations, standard arrival models could not predict arrival pattern adequately. Therefore, a time series model is introduced to propose a better solution to this problem.

\section{LITERATURE REVIEW}

Several researchers worked on traffic arrival pattern. Allsop worked on delay at signalized intersection assuming traffic arrival pattern as Poisson distribution [1]. Mathew described vehicle arrivals are related to time interval between the successive arrival of vehicles and number of vehicle arrive in a given interval of time [2]. Mahalel and Hakkert worked on vehicle arrival patterns in adjacent lanes of a multilane and found that the sequence of traffic arrivals in adjacent lanes as a Markov renewal process [3]. Rengaraju and Rao identified appropriate probability distribution models for vehicle arrivals at uncontrolled intersections [4]. They proposed multivariate distribution for higher traffic volumes under mixed traffic conditions. Ozbay et al. proposed transform expand sampling techniques to model traffic arrival pattern in the signalized intersection [5]. Williams and Hoel predicted seasonal variation of traffic condition in freeways using ARIMA model [6]. Kamarianakis and Prastacos researched on space time modeling of traffic flow. They conducted extensive investigation on traffic data obtained from twenty five loop detectors located in the roads of Athens, Greece [7].

\section{DESCRIPTION OF STUDY AREA}

A section of Route 18 in New Brunswick, New Jersey was modeled using Paramics simulation tool. The starting point of the network is located approximately near the intersection of Route 18 (Memorial Parkway) and Route 27. The end point of the network is located at the intersection of County Road 516 (Old Bridge Matawan Road) and County Road 687 in Old Bridge. The model has seventy six trip generating zones and eleven signalized intersections. Three intersections in the Route 18 arterial road are considered for traffic arrival pattern study. Those are-Naricon Place, South Woodland Avenue and West Ferris Street intersections. Paramics model of the intersections are presented in the following Figure 1.

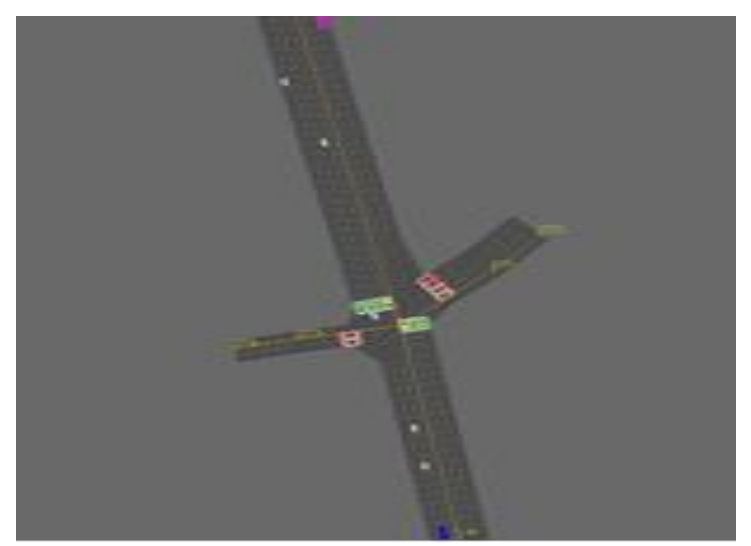

Fig 1(a): Snapshot of Route 18 and Naricon Place intersection modeled in Paramics 


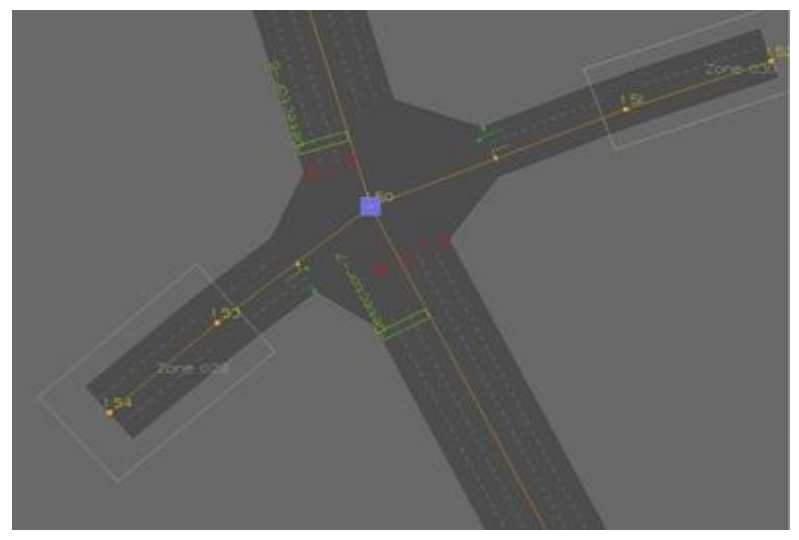

Fig 1(b): Snapshot of Route 18 and South Woodland Avenue intersection modeled in Paramics

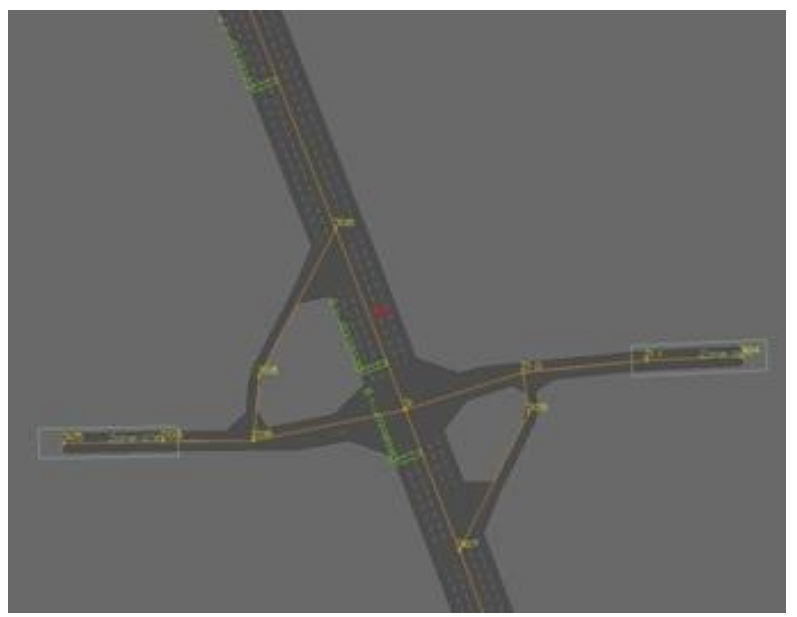

Fig 1(c): Snapshot of Route 18 and West Ferris Street intersection modeled in Paramics

Loop detectors were placed into the Paramics model to collect traffic data. Three detectors were placed for each signalized intersection. Position of detectors at a signalized intersection is shown in the following schematic Figure 2.

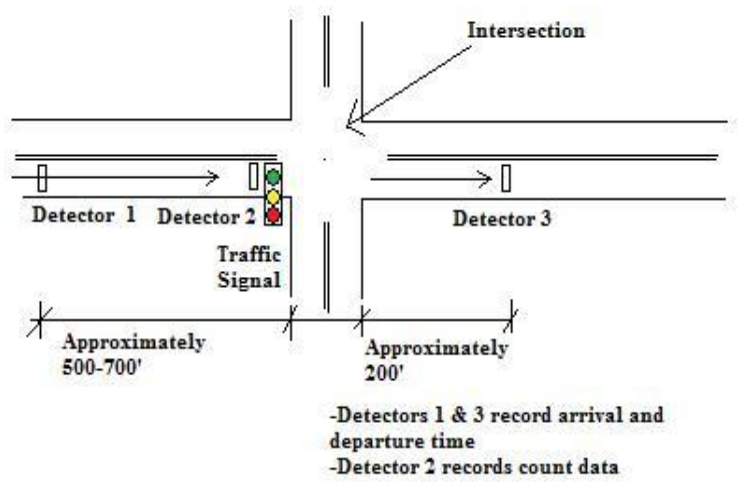

\section{Fig 2: Position of detectors at an intersection}

To study traffic arrival patterns under different demand levels, three demand levels were used for the simulation and evaluation. They were numbered as one to three ranging from low to high presented in the Table 1. Simple two phase signal sequences are considered for each signalized intersection.
Table 1. Different demand levels with through traffic

\begin{tabular}{|l|c|c|}
\hline Demand Level & $\begin{array}{l}\text { Total road } \\
\text { traffic }\end{array}$ & $\begin{array}{l}\text { g/C ratio (Green to } \\
\text { cycle time ratio) }\end{array}$ \\
\hline $\begin{array}{l}\text { Demand 1 (Low } \\
\text { through traffic) }\end{array}$ & $4372 \mathrm{vph}$ & 0.51 \\
\hline $\begin{array}{l}\text { Demand 2 } \\
\text { (Medium high } \\
\text { through traffic) }\end{array}$ & $5462 \mathrm{vph}$ & 0.64 \\
\hline $\begin{array}{l}\text { Demand 3 (High } \\
\text { through traffic) }\end{array}$ & $7109 \mathrm{vph}$ & 0.83 \\
\hline
\end{tabular}

\section{DATA COLLECTION}

Poisson arrival pattern is usually observed in the isolated intersection [8]. In real world, vehicle arrival patterns are more complicated due to upstream signals influence. Traffic arrival patterns can be modeled as binomial, negative binomial, and uniform distribution for simplicity. However, no standard distribution patterns can describe traffic arrival properly [9].Arrival counts per cycle data are obtained from simulation. For three different demand levels, simulations are conducted using five different seed values. Therefore, total fifteen count datasets are obtained for three signalized intersections and each dataset contains two hundred signal cycle arrival counts data of vehicle.

\section{TIME SERIES MODEL}

In many cases, arrival pattern does not fit with specified standard distribution accurately. Therefore, it is important to improve arrival model and find better estimator which can describe arrival pattern at signalized intersection adequately. Time series models can provide solution in this regard. Models for time series data may have many forms and represent different stochastic processes. Autoregressive (AR), Moving Average (MA), Integrated (I) methods are some time series models. Combination of all these three methods is known as Autoregressive moving average (ARIMA), which can perform better than any standard distribution for estimating vehicle arrivals [10].

ARIMA is one of the most powerful tools to fit with timevarying data into time series equations. ARIMA model is usually denoted by ARIMA (p,d,q) where $p=$ autoregressive term, $\mathrm{d}=$ trend term, and $\mathrm{q}=$ moving average term. For example, ARIMA $(1,1,1)$ means it has autoregressive term 1 , trend term 1 , and moving average term 1 . Autoregressive term (p) describes dependency among successive observations. For example, a model with auto regressive term $p=3$ is one in which an observation is predicted by three previous observations. Moving average term (q) describes persistence of random shock wave from one observation to the next. Random shocks are random components of a time series model. Trend term (d) is used to make non-stationary time series stationary. Stationary time series model vary around constant mean, variance, and has no systematic decreasing or increasing pattern [8]. On the other hand, nonstationary time series model has systematic linear, quadratic or other types of trend and unstable in nature. Another issue related to time series model is Autocorrelation. Autocorrelation is a mathematical representation of the degree of similarity between a given time series and a lagged version of itself over successive time interval.

\section{MODEL BUILDING}

It has been observed that some arrival patterns do not fit with standard distribution such as Poisson, binomial, and negative binomial model. Due to stochastic fluctuation of traffic arrivals, standard distribution patterns do not always fit accurately. Therefore, ARIMA (Autoregressive Integrated 
Moving Average) process is used to estimate traffic arrivals. Statistical software such as SAS is used to find out appropriate ARIMA time series model. A comparative study of ARIMA and Poisson arrival models with simulation is then conducted. Three different scenarios are investigated and brief description of each scenario is given in the following Table 2 and ARIMA model is presented in the table 3 .

Table 2. Description of scenarios

\begin{tabular}{|c|l|l|l|}
\hline Scenarios & Demand level & Intersection & $\begin{array}{l}\text { Arrival } \\
\text { type }\end{array}$ \\
\hline $\begin{array}{c}\text { Scenario } \\
1\end{array}$ & $\begin{array}{l}\text { Demand 3 } \\
\text { (high through } \\
\text { traffic) }\end{array}$ & $\begin{array}{l}\text { Route 18 and } \\
\text { Naricon Place }\end{array}$ & $\begin{array}{l}\text { Under } \\
\text { dispersed }\end{array}$ \\
\hline $\begin{array}{c}\text { Scenario } \\
2\end{array}$ & $\begin{array}{l}\text { Demand 2 } \\
\text { (medium } \\
\text { through traffic) }\end{array}$ & $\begin{array}{l}\text { Route 18 and } \\
\text { South } \\
\text { Woodland } \\
\text { Avenue }\end{array}$ & Random \\
\hline $\begin{array}{c}\text { Scenario } \\
3\end{array}$ & $\begin{array}{l}\text { Demand 1 (low } \\
\text { through traffic) }\end{array}$ & $\begin{array}{l}\text { Route 18 and } \\
\text { West Ferris } \\
\text { Street }\end{array}$ & $\begin{array}{l}\text { Over } \\
\text { dispersed }\end{array}$ \\
\hline
\end{tabular}

Table 3. Description of scenarios

Assume, $\mathrm{y}_{\mathrm{t}}=$ observation of headways at time $\mathrm{t}, \mathrm{a}_{\mathrm{t}}=$ current time period

\begin{tabular}{|l|l|l|l|}
\hline Scenarios & $\begin{array}{l}\text { ARIMA } \\
\text { model }\end{array}$ & Equations & Explanation \\
\hline $\begin{array}{l}\text { Scenario 1 } \\
\text { for under } \\
\text { dispersed } \\
\text { arrival }\end{array}$ & $\begin{array}{l}\text { ARIMA } \\
(0,1,1)\end{array}$ & $\begin{array}{l}\mathrm{y}_{\mathrm{t}+1}=\mathrm{yt}- \\
0.89 * \mathrm{a}_{\mathrm{t}}\end{array}$ & $\begin{array}{l}\text { Moving } \\
\text { average factor } \\
\text { is -0.89 }\end{array}$ \\
\hline $\begin{array}{l}\text { Scenario 2 } \\
\text { for random } \\
\text { arrival }\end{array}$ & $\begin{array}{l}\text { ARIMA } \\
(1,2,0)\end{array}$ & $\begin{array}{l}\mathrm{y}_{\mathrm{t}+1}=2 * \mathrm{y}_{\mathrm{t}}+ \\
+0.078 *\left(\mathrm{y}_{\mathrm{t}}-\right.\end{array}$ & $\begin{array}{l}\text { Autoregressive } \\
\text { factor is 0.078 } \\
\left.\mathrm{y}_{\mathrm{t}-1}\right)\end{array}$ \\
\hline $\begin{array}{l}\text { Scenario 3 } \\
\text { for over } \\
\text { dispersed } \\
\text { arrival }\end{array}$ & $\begin{array}{l}\text { ARIMA } \\
(1,2,0)\end{array}$ & $\begin{array}{l}\mathrm{y}_{\mathrm{t}+1}=2 * \mathrm{y}_{\mathrm{t}} \\
+\mathrm{y}_{\mathrm{t}-1}+ \\
0.495 *\left(\mathrm{y}_{\mathrm{t}}-\right.\end{array}$ & $\begin{array}{l}\text { Autoregressive } \\
\text { factor is 0.495 }\end{array}$ \\
\hline
\end{tabular}

Poisson arrival process has an identical character that its headway distribution is exponential. Cumulative arrival time can be obtained by generating random exponential numbers (headways). Then vehicle counts per signal cycle are calculated from the cumulative arrival time.

\section{DATA ANALYSIS}

A comparative study is made to investigate appropriate arrival model between Poisson process and time series model. Using steps of building ARIMA and Poisson arrival model, headways of vehicle are obtained. Cumulative headways are then calculated from headways. Vehicle counts per cycle and variance to mean ratio are calculated using MatLab code. Five criteria are considered for comparative study, such as: (1) Arrival headway distribution of vehicles (2) Histogram of vehicle counts per signal cycle, (3) Estimation of variance to mean (VMR) ratio of arrivals per cycle and (4) Comparative statistical analysis based on goodness of fit tests.

\subsection{Arrival headway of vehicles}

Headway is the arrival time difference between two subsequent vehicles in a lane. Therefore, vehicle headway pattern is closely related with arrival distribution. Headway distribution histograms for different three cases are presented as Poisson (Green color) and ARIMA (Brown color) models are compared with Paramics (Blue color) results in the figure 3. Poisson process has large deviation from simulation comparing with ARIMA arrival model.

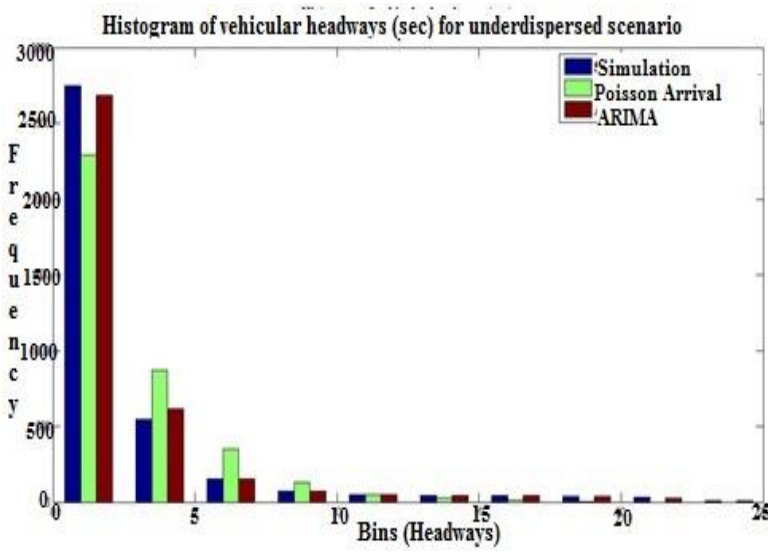

Fig 3(a): Histogram of arrival headways for under dispersed scenario

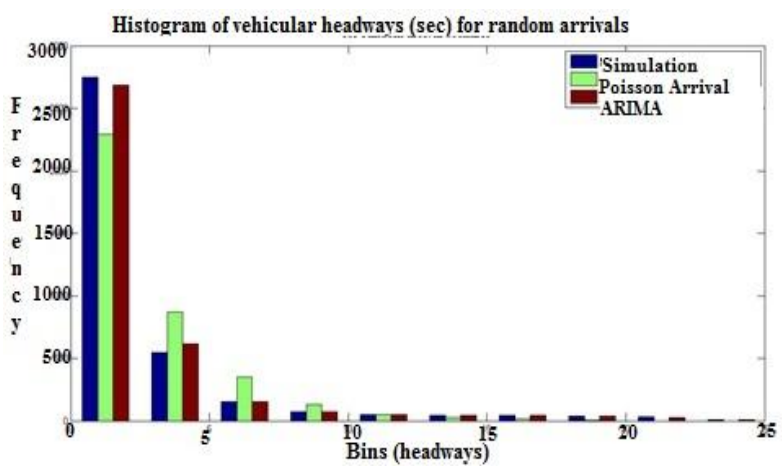

Fig 3(b): Histogram of arrival headways for random arrival scenario

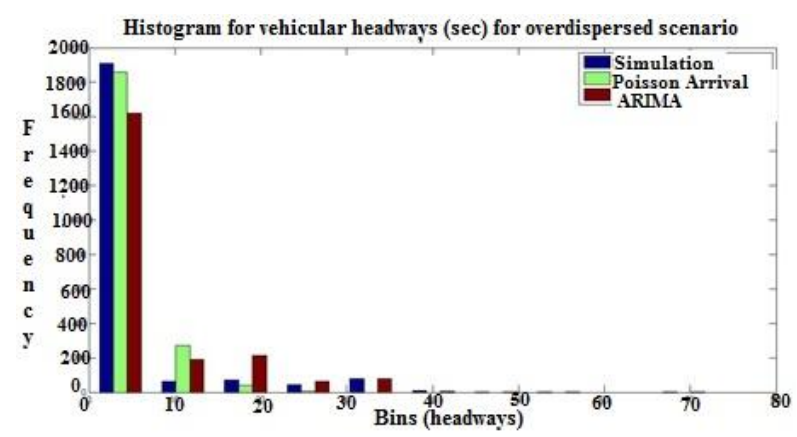

Fig 3(c): Histogram of arrival headways for over dispersed scenario

\subsection{Histogram of vehicle counts per cycle}

Vehicle arrival counts per cycle obtained from simulation are compared with Poisson and ARIMA models in the following Figures 4. Poisson arrival process deviates from simulation result very widely. On the other hand, histogram of ARIMA model is close to the histogram obtained from simulation results. 


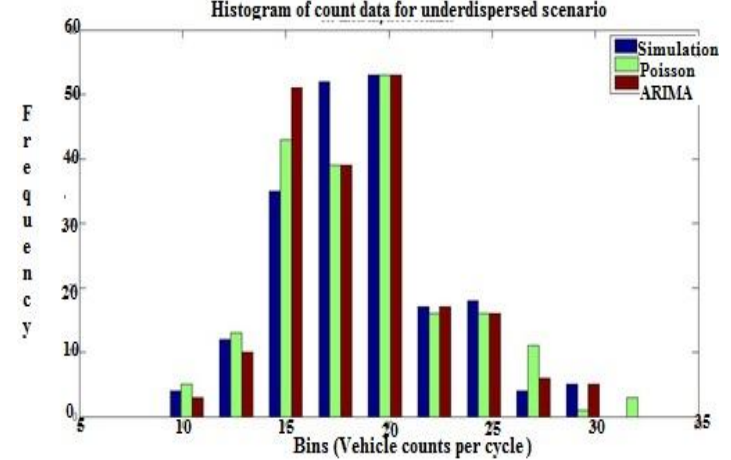

Fig 4(a): Histogram of vehicle counts per signal cycle for under dispersed scenario

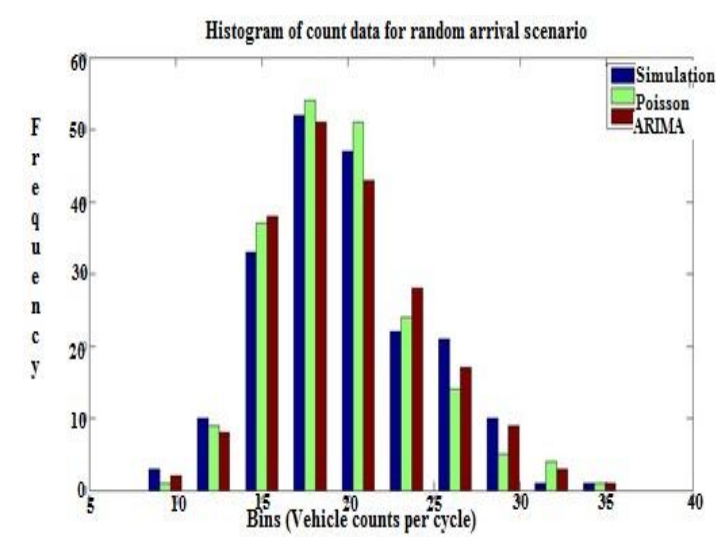

Fig 4(b): Histogram of vehicle counts per signal cycle for random arrival scenario

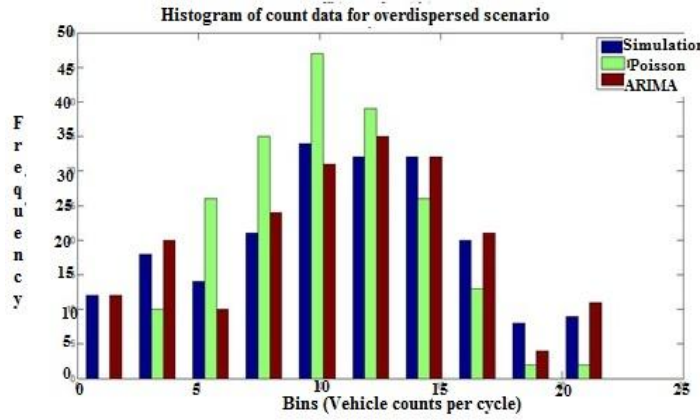

Fig 4(c): Histogram of vehicle counts per signal cycle for over dispersed scenario

\subsection{VMR of arrivals per cycle}

Variance to mean (VMR) ratio is the ratio of variance of arrivals per cycle divided by average arrivals per cycle. VMR is calculated for ARIMA and Poisson arrival models. Then VMR obtained from simulation is compared with the above two arrival models. In scenario 1, Poisson and ARIMA arrival models have $26 \%$ and $6 \%$ deviation respectively from simulation result. Both Poisson and ARIMA arrival models have very small deviation in the scenario 2. Poisson arrival process is shown to be deviated significantly from simulation results in the third scenario. On the other hand, ARIMA model has only $2 \%$ deviation from simulation. Deviation from simulation results are presented graphically in the following Figure 5.

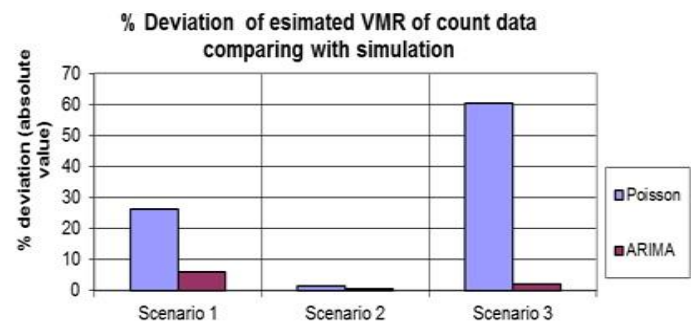

Fig 5: Percent deviation of estimated VMR of arrivals comparing with simulation

\subsection{Comparative statistical analysis}

Goodness of fit tests of count data can provide clear idea about which model performs better between ARIMA and Poisson arrival process. Goodness of fit test describes how well a model fits with a set of observations. The details of goodness of fit test are described in the chapter five. Chisquare $\left(\chi^{2}\right)$ are presented in the following table 4 .

Table 4. Comparative study between Poisson and ARIMA models

\begin{tabular}{|c|c|c|c|c|}
\hline \multirow[b]{2}{*}{ Scenarios } & \multicolumn{4}{|c|}{ Chi-square test } \\
\hline & \multicolumn{2}{|c|}{ Poisson process } & \multicolumn{2}{|c|}{ ARIMA } \\
\hline \multirow[b]{2}{*}{$\begin{array}{c}\text { Scenario } \\
1\end{array}$} & t-statistics & 8.65 & t-statistics & 3.608 \\
\hline & $\begin{array}{l}\text { Critical } \\
\text { value }\end{array}$ & 11.1 & $\begin{array}{l}\text { Critical } \\
\text { value }\end{array}$ & 9.488 \\
\hline \multirow[b]{2}{*}{$\begin{array}{c}\text { Scenario } \\
2\end{array}$} & t-statistics & 7.5 & t-statistics & 2.841 \\
\hline & $\begin{array}{l}\text { Critical } \\
\text { value }\end{array}$ & 11.1 & $\begin{array}{l}\text { Critical } \\
\text { value }\end{array}$ & 12.59 \\
\hline \multirow{2}{*}{$\begin{array}{c}\text { Scenario } \\
3\end{array}$} & t-statistics & 8.8 & t-statistics & 0.972 \\
\hline & Critical value & 9.49 & Critical value & 9.49 \\
\hline
\end{tabular}

From the above Table 4, both Poisson and ARIMA models fit with the simulation based on chi-square and likelihood ratio tests in all cases. In all three scenarios, $\chi^{2}<=\chi^{2}$ critical and However, ARIMA arrival model shows smaller tstatistics comparing with Poisson arrival model. Therefore, we can conclude that ARIMA model performs better than Poisson arrival process

\section{CONCLUSION}

All of the above observations prove that ARIMA model is a better estimator comparing with Poisson arrival model. However, ARIMA is more complicated approach and it is time consuming to produce results. On the other hand, Poisson arrival model is simple and easy to calculate. Poisson arrival distributions are observed at vehicle arrivals of upstream signals in a arterial road. In many cases, arrival count data do not fit with any standard distribution. Later, ARIMA model is used to predict arrival headways precisely. In comparison with simulation, ARIMA model performs better than Poisson arrival process. ARIMA model can be used to predict traffic forecast more precisely and work as a bridge to fill gap between theoretical traffic arrival models and real world traffic scenario. The techniques of time series modeling could be investigated not only for freeways under various vehicle arrival patterns, but also under very high traffic congested situation where vehicle platoon effect is a common phenomenon. 


\section{REFERENCES}

[1] Allsop, R.E. "Delay at a Fixed Time Traffic Signal-I: Theoretical Analysis". Transportation Science, Vol. 6, 1972, pp. 260-285.

[2] Mathew T.V., "Transportation Systems Engineering, Chapter 12: Vehicle arrival model headway", nptel. February 2014.

[3] Mahalel D., Hakkert A.S., "Traffic arrival patterns on a cross section of a multilane highway." Transportation Research Part A: General, July 1883, Publisher Elsevier.

[4] Rengaraju V.R., Rao T.V., "Vehicle-Arrival Characteristics at Urban Uncontrolled Intersections", Journal of Transportation Engineering, Vol. 121, No. 4, July/August 1995, pp. 317-323.

[5] Ozbay K., Chen J., and Boile M., "Modeling Traffic Arrivals for Estimating Delays at Signalized Intersections". Prepared for the Transportation Research Board, Washington, D.C., 2005.
[6] Willams B.M., Hoel L.A., "Modeling and forecasting vehicular traffic flow as a seasonal ARIMA process: Theoretical Basis and Empirical Results". Journal of Transportation Engineering, ASCE, November 2003.

[7] Kamariannakis Y., Prastacos P., "Space-time modeling of traffic flow". Computers \& Geosciences 31, Page 119-113, 2005.

[8] Kadiyali, L.R. "Traffic Engineering and Transportation Planning”. Khanna Publishers, New Delhi, 1987.

[9] Adolf D. May. "Fundamentals of Traffic Flow". Prentice - Hall, Inc. Englewood Cliff New Jersey 07632, second edition, 1990.

[10] Huddleston, E., Jones A. SAS/ETS 9.2 User's Guide, SAS 9.2 documentations. "The ARIMA Procedure". March 2008.

[11] http://support.sas.com/documentation/cdl/en/etsug/6037 2/HTML/default/viewer.htm\#arima_toc.htm. [Jan 15, 2011]. 